\title{
Caffeine is a risk factor for osteopenia of prematurity in preterm infants: a cohort study
}

\author{
Ebtihal Ali ${ }^{1,4^{*}}$ (D), Cheryl Rockman-Greenberg ${ }^{2,4}$, Michael Moffatt ${ }^{1,2,4}$, Michael Narvey ${ }^{2,4}$, Martin Reed ${ }^{3}$ \\ and Depeng Jiang ${ }^{1}$
}

\begin{abstract}
Background: Caffeine, the most commonly used medication in Neonatal Intensive Care Units, has calciuric and osteoclastogenic effects.

Methods: To examine the association between the cumulative dose and duration of therapy of caffeine and osteopenia of prematurity, a retrospective cohort study was conducted including premature infants less than 31 weeks and birth weight less than $1500 \mathrm{~g}$. Osteopenia of prematurity was evaluated using chest X-rays on a biweekly basis over 12 weeks of hospitalization.

Results: The cohort included 109 infants. 51\% had osteopenia of prematurity and $8 \%$ had spontaneous rib fractures. Using the generalized linear mixed model, caffeine dose and duration of caffeine therapy showed a strong association with osteopenia of prematurity. Steroids and vitamin D were also significantly correlated with osteopenia of prematurity while diuretic use did not show a statistically significant effect.

Conclusion: The cumulative dose and duration of therapy of caffeine, as well as steroid are associated with osteopenia of prematurity in this cohort. Future studies are needed to confirm these findings and determine the lowest dose of caffeine needed to treat effectively apnea of prematurity.
\end{abstract}

Keywords: Premature infants, Osteopenia of prematurity, Metabolic bone disease, Caffeine

\section{Background}

Approximately $80 \%$ of bone mineralization of the newborn takes place during the third trimester of pregnancy because of the high rate of intrauterine growth [1]. Thus, preterm infants whom deprived of that period, are born with less bone mineral content. In addition, physiological adaptation of bone to extra-uterine life leads to an increase in bone resorption. This process occurs earlier in preterm than in term infants and can be accompanied by high risk of bone fragility and fractures [2]. Bone resorption appears to be more important than

\footnotetext{
* Correspondence: eali@hsc.mb.ca

${ }^{1}$ Community Health Sciences Department, Faculty of Health Sciences, University of Manitoba, MS361K, 820 Sherbrook St, Winnipeg, MB R3A 1R9, Canada

${ }^{4}$ Child Health Program, Winnipeg Regional Health Authority, Winnipeg, MB, Canada

Full list of author information is available at the end of the article
}

decreased bone formation in the pathogenesis of osteopenia of prematurity $(\mathrm{OP})[3]$.

Almost $10 \%$ of infants are born prematurely worldwide, representing more than 15 million births every year. The incidence and severity of osteopenia of prematurity increase as the birth weight (BW) and gestational age (GA) decrease [4]. Preterm infants are known to have a lower bone density (BMD) and bone mineral content (BMC) [2] at the corrected age of term, as well as a lower weight and Ponderal index [5]. Moreover, preterm infants have lower bone strength at the distal tibia and radius compared to age and sex-matched controls, when assessed with computerized tomography as young adults [6].

In 1989, the incidence of OP was $55 \%$ of infants $<1000 \mathrm{~g}$ and $23 \%$ of infants $<1500 \mathrm{~g}$ at birth. A notable finding at this time was that OP risk showed an inverse relationship to lower GA and a direct relationship to duration of parenteral nutrition [7]. In 2009, a study 
reported pathological fractures in $30 \%$ of preterm infants with osteopenia [8].

Caffeine is the most commonly consumed pharmacologically active compound in the world [9]. In the neonatal intensive care units (NICU), it is one of the most commonly prescribed drugs to treat apnea of prematurity [10]. The half-life in neonates is 72-96 h (range: 40-230 h) and the time to peak serum concentration after oral administration ranges from $30 \mathrm{~min}$ to $2 \mathrm{~h}$, whereas $86 \%$ of caffeine is excreted unchanged in urine [11]. The liver enzymes responsible for caffeine metabolism mature progressively with increasing GA. Girls were reported to have a higher rate of caffeine metabolism than boys [12]. Clearance of caffeine in infants born prematurely is markedly lower and the volume of distribution is higher than infants at term-equivalent age and beyond. Elimination of caffeine is initially depressed in extremely premature infants and then increases nonlinearly to final assessment at 6 weeks postnatal age [13]. It is well established that caffeine causes calciuria and creates negative calcium balance in preterm rats especially after prolonged use with compensatory increase in PTH to normalize serum calcium at the expense of bone [14-16]. Tolerance to the renal effects of caffeine does not develop with chronic use [17].

In a study in mice, it was found that caffeine effectively enhanced the osteoclastogenesis from bone marrow hematopoietic cells and bone resorption activity as assessed by the pit formation assay [18]. In another study, BMD was significantly lower in growing rats supplemented with $0.2 \%$ caffeine in diets for 20 weeks compared with the control group. Additionally, the calcium content in tibiae and femora of caffeine-treated rats was also lower, and the osteoclastogenesis of bone marrow cells isolated from caffeine-treated rats was markedly enhanced as compared with that in the control group. Taken together, these results suggest that caffeine reduces BMD through the enhancement of osteoclastogenesis and its calciuric effect [19].

Based on existing studies we hypothesize that caffeine usage, cumulative dose or duration of usage are associated with OP. and this association exists even when controlled for the effects of other neonatal risk factors.

The primary outcome of this study was to determine the effect of the cumulative dose and the duration of caffeine on OP. Other covariates of interest were included in the analysis, steroids and diuretics cumulative dose vitamin $\mathrm{D}$ intake, and maternal parity.

\section{Methods}

This retrospective quantitative descriptive pilot cohort study was conducted at Health Sciences Centre in Winnipeg, Manitoba, Canada, from October 2007 to June 2012. Premature infants $<31$ weeks gestation and birth weight $<1500 \mathrm{~g}$ infants were included, all infants had at least 12 weeks of hospital stay. It is difficult to implement case control study having infants with no caffeine intake as all admitted infants less than 33 weeks are on caffeine by hospital guidelines. We excluded infants with congenital anomalies, infants with gut surgery affecting feeding, infants with non-osteopenic fractures, and infants with insufficient data to analyze. The data were collected from the charts in the medical record. The study included 109 infants who met the inclusion criteria. Cases of osteopenia were defined if they have radiological evidence of osteopenia of prematurity.

The data included: GA in weeks, gender, birth weight, average biweekly weight, total parenteral nutrition (TPN) days, and maternal parity level. The later was recorded as categorical data; high if $>5$, moderate if 3 or 4 and low parity if 1 or 2 . Average biweekly vitamin D intake was included as longitudinal data. Serum phosphate measurements were collected on biweekly basis $+/-1$ week. The phosphate level was recorded as categorical data; high if $>2.5 \mathrm{mmol} / \mathrm{l}$, normal if between 1.8 to $2.5 \mathrm{mmol} / \mathrm{l}$, low if between 1.3 to $1.8 \mathrm{mmol} / \mathrm{l}$ and very low if $<1.3 \mathrm{mmol} / \mathrm{l}$. The radiological data ( $\mathrm{X}$ rays) were reviewed and interpreted, by a pediatric radiologist and the writer, (the Cohen's kappa was 0.83 and 95\% CI 0.82 to 0.084 , which indicates very good interrater agreement) [20] both did not know the infants 'clinical status or biochemical data at the time of the interpretation, on a biweekly basis at least for the first 12 weeks of life, using Koo et al. criteria [21]. Table 1.

The descriptive statistics (means and standard deviations) or (median and quartile) were used to summarize the characteristics of the sample. As the grade level of bone of newborn infants was measured fortnightly from birth to 12 weeks old, the binary outcome variables (OP) $(0,1)$, are longitudinal with up to 7 time points. It was preferable to include grade 1 and 2 of OP together, as the differentiation between the two grades is very subjective. Grade 3 OP was easier to distinguish, as callus formation was indicative of previous underlying spontaneous fracture. Due to the limited sample size, we dichotomized the radiological grading of OP by collapsing grades 1, 2 and 3 together as OP. At the same time, we

\begin{tabular}{ll} 
Table $\mathbf{1}$ Koo et al. Criteria for osteopenia of prematurity \\
\hline Grades & Description \\
\hline Grade 0: & $\begin{array}{l}\text { Normal density of bone cortex along shaft with normal } \\
\text { dense white line at metaphysis and normal band of } \\
\text { lucency, and thinning of cortex. }\end{array}$ \\
Grade 1: & $\begin{array}{l}\text { Loss of dense white line at the metaphysis, increased } \\
\text { sub-metaphyseal lucency and thinning of cortex. }\end{array}$ \\
Grade 2: & $\begin{array}{l}\text { Changes in grade 1 plus irregularity and fraying of } \\
\text { metaphysis, with splaying and cupping that is indicative } \\
\text { of rickets. }\end{array}$ \\
Grade 3: & Indications of rickets with evidence of fractures.
\end{tabular}


considered grade 0 as normal. We assessed the OP status for every two weeks, Therefore, the generalized linear mixed model was used for repeated measures of binary outcome (OP status) [22].

The cumulative dose of caffeine were included in the generalized linear mixed model as covariates. Other covariates added to the generalized linear mixed model included doses of steroids, diuretics, vitamin D intake, and other demographic variables such as GA in weeks and gender. Vitamin D intake, average biweekly weight, and serum phosphate were treated as time-varying covariates. To examine whether the effect of duration of caffeine treatment on OP, a generalized linear mixed model was fitted by including the interaction between caffeine dosage and duration of therapy, and other covariates. The statistical analyses were carried out using SAS 9.3 (SAS Institute, Cary, NC). All $p$-values are twosided, and significance was set at a value of 0.05.

\section{Results}

The initial cohort included 335 preterm infants, with GA of less than 31 weeks and birth weight less than $1500 \mathrm{~g}$, who were admitted to the NICU between July 2007 and July 2012. Of these 335 infants, 35 infants died, 5 infants were transferred to other facilities and 3 others who had surgical necrotizing enterocolitis with short bowel syndrome were also excluded. Out of the remaining 292 infants, the final study group included 109 infants who had the required 12 weeks of hospital stay, radiological data and laboratory data to analyze.

The raw data were examined for any outliers and influential points before the start of the analysis. The results of GA, birth weight, sex, maternal parity and (TPN) duration are shown in Table 2 as mean $\pm 2 \mathrm{SD}$, and average biweekly weight and vitamin $\mathrm{D}$ intake in Table 3 as mean \pm 2 SD.

There were 8 infants with bone fractures (8\%). The fractures involved the right and left lower ribs and none

Table 2 The cohort biometric data

\begin{tabular}{ll}
\hline Variables & \\
\hline Gestational Age (weeks) (mean \pm 2SD) & $27 \pm 1.6$ \\
Birth Weight (grams) & $665 \pm 229$ \\
Mean \pm 2 SD & \\
Male/Female & 54 male/55 female \\
Maternal Parity & $85(77.9 \%)$ \\
Low parity $<2$ & $16(14.6 \%)$ \\
Moderate parity2-4 & $8(7.5 \%$ \\
High parity $>4$ & \\
TPN days & 21 \\
(Median) & 11,32 \\
Quantiles &
\end{tabular}

of them had a spontaneous fracture of the humerus. The prevalence of OP based on Koo et al. in this cohort was $51.3 \%$.

All the infants received caffeine during their hospital stay, starting day one. The mean \pm 2 SD dose of caffeine was $425.33 \pm 235.2 \mathrm{mg}$ as a cumulative dose and the mean \pm 2 SD duration of caffeine therapy was $60 \pm$ 45.8 days. The mean \pm 2 SD dose of caffeine was $7.95 \pm$ $2.7 \mathrm{mg}$ per $\mathrm{kg}$ per day and the range of caffeine dose was (4.1-15.6 $\mathrm{mg} / \mathrm{kg} /$ day) including the loading, the maintenance dose and the mini-load doses. The usual starting load was $10 \mathrm{mg} / \mathrm{kg}$ followed by maintenance of $5-7 \mathrm{mg} /$ $\mathrm{kg} /$ day and the infant received mini-loads of caffeine inbetween according to the severity of apnea of prematurity as long as the heart rate was less than 180 beat $/ \mathrm{min}$. During the study time, there was no systematic protocol to monitor the serum caffeine level.

There were 79 infants who received diuretics (73\%). The median diuretic dose was $5.9 \mathrm{mg}$ with 1 st and 3rd quartiles of 1, 25.8 during the hospital stay. The steroids were calculated as dexamethasone dose or equivalent as $100 \mathrm{mg}$ of hydrocortisone are equal to $20 \mathrm{mg}$ of dexamethasone. In this cohort, the median steroid dose was $2 \mathrm{mg}$ and the 1 st and $3 \mathrm{rd}$ quartiles were $0,42 \mathrm{mg}$ during the hospital stay.

We first fitted a logistic regression model to examine each individual variable associated with the probability of OP, including gestational age, average biweekly birth weight, maternal parity, TPN duration, vitamin D intake, and serum phosphate level, duration of caffeine treatment and the cumulative doses of caffeine, steroids, and diuretics. The results are presented in Table 4 . Table 4 shows that lower gestational age and average biweekly weight are correlated with OP. Similarly, higher caffeine cumulative dose and longer caffeine duration of therapy showed a statistically significant correlation with OP $\left(p^{*}\right.$ $<0.05)$. In the univariate model; steroids doses, TPN days and average biweekly intake of vitamin D displayed significant correlation with OP. On the contrary, maternal parity, serum phosphate and diuretics were not associated with OP $(p>0.05)$ in this study. The maternal parity was analyzed as low parity if less than 2 and moderate parity if more than 2 . Similarly, serum phosphate was categorized as very low if less than $1.3 \mathrm{mmol} / \mathrm{l}$ and low if between 1.3 and $1.8 \mathrm{mmol} / \mathrm{l}$ and normal if more than $1.8 \mathrm{mmol} / \mathrm{l}$.

Then we fitted a logistic multivariable generalized linear mixed model with gestational age, average biweekly weight, cumulative dose of caffeine, cumulative steroids dose and vitamin D considering the clinical importance and statistical significance at univariate analysis. The results are showed in Table 5 .

Table 5 indicates that higher cumulative dose of caffeine is associated with an increase in the probability of 
Table 3 The average biweekly weight and vitamin D intake of the study cohort

\begin{tabular}{lllllll}
\hline & Week1-2 & Week3-4 & Week5-6 & Week7-8 & Week9-10 & Week11-12 \\
\hline Average weight in grams (mean \pm 2SD) & $993 \pm 23$ & $1108 \pm 2$ & $1335 \pm 29$ & $1660 \pm 4$ & $1984 \pm 4$ & $2348 \pm 5$ \\
Average Vitamin D in units (mean \pm 2SD) & $392 \pm 35$ & $555 \pm 37$ & $737 \pm 33$ & $834 \pm 29$ & $947 \pm 29$ & $1034 \pm 32$ \\
\hline
\end{tabular}

OP. The effect of caffeine was true even when we controlled the effect of other variables (average weight, the gestational age, steroid and vitamin D). The odds of OP is 1.10 times (95\%CI: 1.05-1.15) higher for every $5 \mathrm{mg} / \mathrm{kg}$ increase in cumulative caffeine dose when other factors are controlled.

The steroid dosage has a statistically significant result in predicting OP with $\left(p^{*}<0.0001\right)$ (estimated Odds ratio $=1.1$ and CI: $1.005-1.20$ ).

The results showed that the average biweekly vitamin D intake, both included in the diet and supplemented, had a negative correlation with the OP $\left(p^{*}<0.0001\right)$. The probability of OP is decreased by $0.4 \%$ when vitamin D increased from 400 to 800 units.

Figure 1 shows the effect of increasing caffeine dosage on the probability of OP over time in different gestational age ( 25 weeks GA $=15$ infants and 30 weeks GA $=25$ infants) based on the above fitted logistic generalized linear mixed model.

To examine whether the effect of duration of caffeine treatment, we fitted another generalized linear mixed model by including the interaction between caffeine dosage and duration of therapy, and other covariates, the results are showed in Table 6. This table shows that, the average caffeine dose, caffeine duration of therapy as

Table 4 Factors associated with OP: Results of univariate analysis

\begin{tabular}{llll}
\hline Variables & Estimate & Standard Error & $P$ value \\
\hline Gestational age (weeks) & -0.645 & 0.147 & $<0.001^{*}$ \\
Average biweekly weight (grams) & 0.0006 & 0.0002 & $0.006^{*}$ \\
Caffeine cumulative dose (mg) & 0.005 & 0.001 & $<0.001^{*}$ \\
Caffeine duration (days) & 0.051 & 0.013 & $<0.001^{*}$ \\
Steroids cumulative dose (mg) & 0.09 & 0.046 & 0.038 \\
TPN duration (days) & 0.034 & 0.012 & $0.005^{*}$ \\
Vitamin D (units) & -1.863 & 0.36 & $<0.001^{*}$ \\
Diuretics cumulative dose (mg) & 0.003 & 0.002 & 0.20 \\
Serum phosphate (mmol/l) & & & 0.57 \\
$\quad$ Phosphate <1.3 & -0.09 & 0.16 & 0.74 \\
$\quad$ Phosphate (1.3-1.8) & 0.11 & 0.33 & \\
$\quad$ Phosphate $>1.8$ (ref) & & & 0.96 \\
Maternal Parity & & & \\
$\quad$ Low parity & -0.016 & 0.42 & \\
Moderate Parity (ref) & & &
\end{tabular}

* Means significant well as the interaction between caffeine dose and duration of caffeine treatment has a statistical significant correlation with OP even when controlling for the effects of gestational age, weight and vitamin $\mathrm{D}(p<0.05)$.

Based on the model in Table 6, Figs. 2 and 3 show the effect of duration of caffeine usage on the probability of OP based on the logistic model. The probability of OP increased in 25 weeks preterm infants (15 infants), is higher than the 30 weeks preterm infants (25 infants). The figure exhibited that the lower the gestational age the higher the probability of osteopenia over prolonged caffeine use, even when controlling caffeine dose, steroid dose, birth weight, and vitamin $\mathrm{D}$.

\section{Discussion}

Although the overall survival of extreme low birth weight infants has improved over the past 2 decades, these infants continue to have significant comorbidities. The prevalence of OP in our study is similar to that previously reported in the literature and suggests that $\mathrm{OP}$ remains a significant comorbidity in extreme low birth weight infants and puts them at increased risk for spontaneous fractures during the NICU stay. Our results are consistent with this concept, the younger and smaller the babies, the higher the incidence of OP.

The results of this study revealed a strong correlation between caffeine treatment and the presence of OP. Despite caffeine's effect on treating apnea of prematurity with favorable long-term outcomes [23], our study revealed a strong association between cumulative dosage and duration of treatment with caffeine and OP even when controlling for the effect of other risk factors. The results show that the adverse effect of caffeine is more evident in lower gestational age infants, which may be

Table 5 Results from Multivariable generalized linear mixed model

\begin{tabular}{llll}
\hline Effect & $\begin{array}{l}\text { Estimate } \\
\text { (logit) }\end{array}$ & $\begin{array}{l}\text { Standard } \\
\text { Error }\end{array}$ & $P$ value \\
\hline Intercept & 5.63 & 5.59 & 0.321 \\
$\begin{array}{l}\text { Caffeine Cumulative Dose (mg) } \\
\begin{array}{l}\text { Steroid Cumulative Dose } \\
\text { (mg) }\end{array}\end{array}$ & 0.39 & 0.05 & $0.007^{*}$ \\
$\begin{array}{l}\text { Vitamin D (units) } \\
\text { Average Biweekly Weight }\end{array}$ & -1.64 & 0.05 & $0.035^{*}$ \\
$\begin{array}{l}\text { (grams) } \\
\text { Gestational age (weeks) }\end{array}$ & -0.01 & 0.0001 & $0.006^{*}$ \\
\hline
\end{tabular}

$p^{*}=$ significant value 


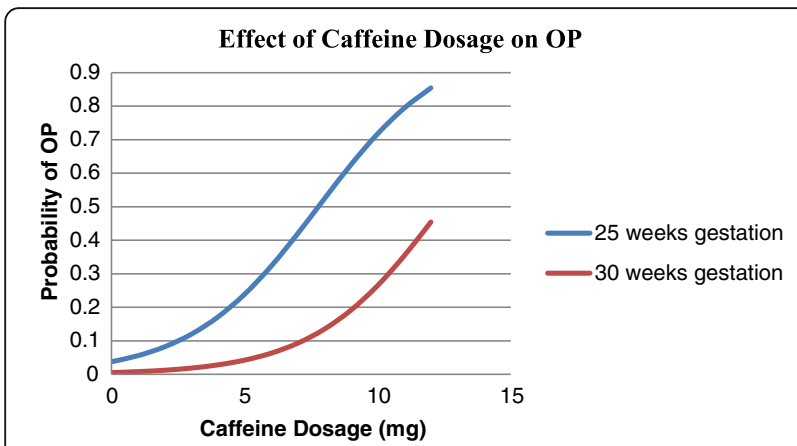

Fig. 1 Probability of OP with increasing caffeine dosage at 25 weeks and at 30 weeks gestational age based on the logistic model

explained by the prolonged half-life of caffeine in their bodies due to diminished kidney abilities to eliminate the caffeine. Furthermore, extreme preterm infants have immature liver enzymes and are unable to catabolize caffeine leading to a prolonged effect causing calciuria and osteoclastogenesis $[14,19]$.

In contrast to the current study results, a retrospective study done by Viswanathan et al. (2014), showed that there was no difference in duration of caffeine use between cases of OP and the control group. Viswanathan et al. did not calculate caffeine dose, only caffeine duration was tracked between cases and controls. Additionally, in the Viswanathan et al. (2014) study, infants with spontaneous rib fractures were included in the control group if there was no radiological evidence of OP. In our study, the osteopenic fractures were encompassed in the cohort data and identified as having severe grade osteopenia. The average duration of caffeine treatment in both groups in the Viswanathan et al. study was 40 days, while in our study, the average duration of caffeine treatment was 60 days [24].

Our current study was a retrospective one and there was no accurate documentation of maternal

Table 6 Estimates with interaction of caffeine and duration of treatment

\begin{tabular}{llll}
\hline Effect & $\begin{array}{l}\text { Estimate } \\
\text { (logit) }\end{array}$ & $\begin{array}{l}\text { Standard } \\
\text { Error }\end{array}$ & $P$ \\
\hline Intercept & 3.39 & 5.99 & 0.57 \\
Average Caffeine dose $(\mathrm{mg} / \mathrm{kg} / \mathrm{d})$ & 0.24 & 0.09 & $0.029^{*}$ \\
$\begin{array}{l}\text { Duration of caffeine treatment (days) } \\
\text { Caffeine dose* Duration of caffeine }\end{array}$ & 0.64 & 0.27 & $0.02^{*}$ \\
treatment (days) & 0.07 & 0.04 & $0.05^{*}$ \\
$\begin{array}{l}\text { Steroid cumulative dose (mg) } \\
\text { Vitamin D (units) }\end{array}$ & 0.09 & 0.05 & 0.07 \\
Average biweekly Birth Weight & -1.86 & 0.36 & $0.04^{*}$ \\
(grams) & -0.06 & 0.02 & $0.001^{*}$ \\
Gestational age (weeks) & -0.64 & 0.15 & $0.001^{*}$ \\
\hline$p^{*}$ Indicates significant level & & &
\end{tabular}

$p^{*}$ Indicates significant level

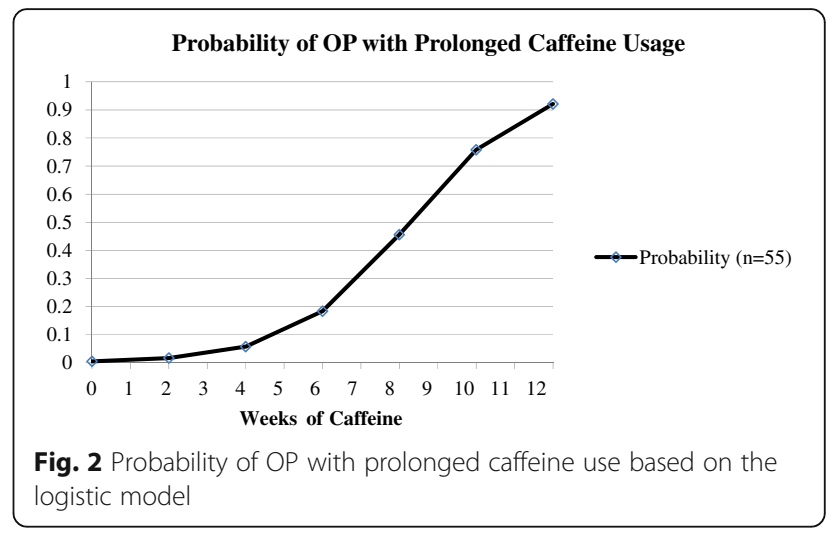

caffeine intake during pregnancy and lactation time. However, it is worth mentioning that in an animal study, maternal caffeine intake negatively affected bone formation and development [25]. Thus our results may still imply an effect of maternal caffeine exposure either in utero or through mother's breast milk and donor breast milk. However, the high doses of caffeine prescribed for apnea of prematurity have paramount contribution to OP.

In this study, there was no difference between male and female infants regarding OP, which is in agreement with another comparable study [26]. But our results do differ from other published studies which found that male infants have higher bone density than females when comparing preterm male and female infants with male and female full term newborns. Such an observation may follow a recognizable trend for testosterone hormone in utero [27, 28].

This study showed significant effect of TPN duration on the development of OP but this effect disappeared when we controlled for other risk factors. This can be explained by considering that other factors contribute more to OP, and that TPN contains the maximum amount of calcium and phosphate according to the

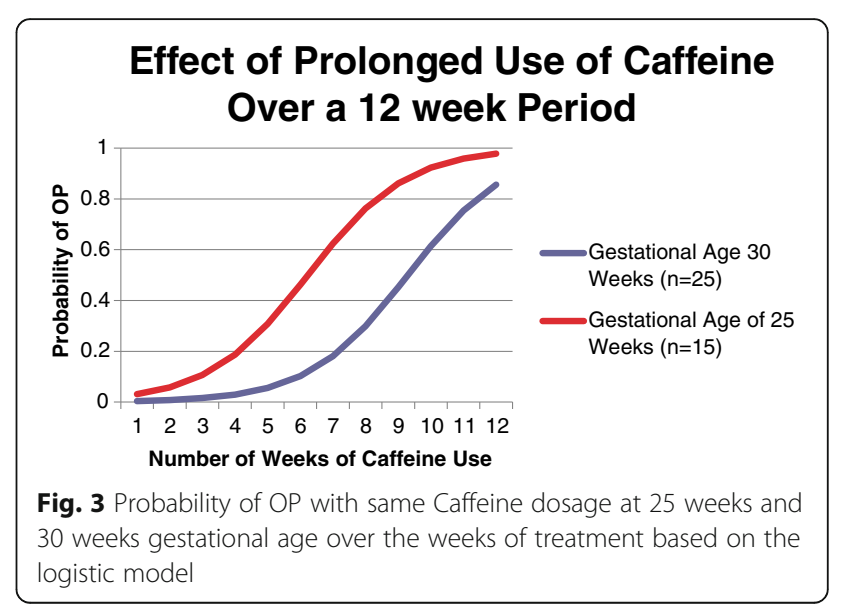


maximum solubility allowed [29]. In this study, TPN duration count included the null per os days as well as partial feeding days. During the study time, TPN is provided till the infant can tolerate the full enteral feeding.

Although Backström et al. suggested that serum phosphate levels lower than $1.8 \mathrm{mmol} / \mathrm{L}(5.5 \mathrm{mg} / \mathrm{dl})$ may have a diagnostic sensitivity of $100 \%$ and specificity of $70 \%$ for OP [30], in our study, serum phosphate on biweekly basis did not show a statistically significant correlation with OP. No other published studies have examined serum phosphate as a longitudinal marker over the hospital stay. Yet, serum phosphate is among the minerals that are regulated tightly, and the average biweekly record may not represent the real situation of serum phosphate in infants on TPN for the first week at least and partial feeding for another week. In agreement with our results, Aly et al., (2005) found that serum phosphate as a single reading at birth was not correlated with OP in preterm infants [27]. In another study serum phosphate and serum alkaline phosphatase were correlated with OP later in infancy, which could be explained by the other confounding factors and medications received that affect premature bone in early life in NICUs [31, 32].

While it is documented that the number of previous pregnancies of a healthy mother correlated negatively with BMD measurements, the effect of previous pregnancies did not show the same effect on infants' bone formation. This supports the fact that an infant acquires the needed minerals and vitamin from the mother's body with active transport against the concentration gradient ignoring the mother's general status [33]. In our study, there was no significant effect of maternal parity on OP. On the other hand, this cohort study with limited sample size did not have enough high parity mothers to detect a correlation, and thus further research is needed that includes high parity mothers.

Our study results show a statistically significant correlation between OP and steroid cumulative dose, while diuretics did show a positive trend in relation to OP. This correlation did not reach statistical significance. This result can be explained by the short duration of diuretics use and the relative small sample size. The use of high dose of caffeine that has a diuretic effect might explain the lower need for the diuretic use.

\section{Conclusions}

We conclude that caffeine has a strong association with OP. As limit of viability continues to decrease with $70 \%$ survival of infants between 24 and 26 weeks, OP will continue to increase and will results in significant morbidity in childhood and adulthood unless strategies to mitigate risk factors are developed. Our study was limited by the small sample size. The study was conducted at one center, and thus the results may not be generalizable on a wider scale. Further studies are needed to determine effective lower caffeine dosage, different ventilation strategies, adequate vitamin D intake, and passive movement as all these can provide protection against $\mathrm{OP}$.

\begin{abstract}
Abbreviations
BMC: Bone mineral content; BMD: Bone mineral density; BW: Birth weight; GA: Gestational age; NICU: Neonatal intensive care unit; OP: Osteopenia of prematurity; PTH: Parathyroid hormone; TPN: Total parenteral nutrition
\end{abstract}

\section{Acknowledgements}

I acknowledge Mr. Lin Xue and Miss. Aliaa El Tobgy for their help in the data management.

\section{Funding}

This study was not funded from any source.

\section{Availability of data and materials}

Data will not be shared. The data will be used for other studies.

\section{Authors' contributions}

Dr. EA have made the acquisition of data, analysis and interpretation of data and discussion writing. Dr. CRG and MN have been involved in drafting the manuscript and revising it critically for important intellectual content. Dr. MM have made substantial contributions to conception and design ensuring that questions related to the accuracy or integrity of any part of the work are appropriately investigated and resolved. Dr. MR agreed to be accountable for all aspects of the work related to the radiological data interpretation and drafting the manuscript. Dr. DJ have been involved in all stages of this study and drafting the manuscript and given final approval of the version to be published. All authors read and approved the final manuscript.

\section{Ethics approval and consent to participate}

The study was approved by the Health Research Ethics Board (HREB) at University of Manitoba number\# H2013: 231, and the Health Sciences Center Research Impact Approval from the Health Science Center. Number\# RI2013: 088. The included data were retrospective data from medical records and did not include any identifying information. Consent to participate is not applicable for this study.

\section{Consent for publication}

Not applicable.

\section{Competing interests}

The authors declare that they have no competing interests.

\section{Publisher's Note}

Springer Nature remains neutral with regard to jurisdictional claims in published maps and institutional affiliations.

\section{Author details}

${ }^{1}$ Community Health Sciences Department, Faculty of Health Sciences, University of Manitoba, MS361K, 820 Sherbrook St, Winnipeg, MB R3A 1R9, Canada. ${ }^{2}$ Department of Pediatrics and Child Health, Faculty of Health Sciences, University of Manitoba, Winnipeg, MB, Canada. ${ }^{3}$ Department of Radiology, Faculty of Health Sciences, University of Manitoba, Winnipeg, MB, Canada. ${ }^{4}$ Child Health Program, Winnipeg Regional Health Authority, Winnipeg, MB, Canada.

Received: 9 September 2015 Accepted: 28 December 2017 Published online: 22 January 2018

\section{References}

1. Specker B. Nutrition influences bone development from infancy through toddler years. J Nutr. 2004;134(3):691S-5S.

2. Bowden LS, Jones CJ, Ryan SW. Bone mineralisation in ex-preterm infants aged 8 years. Eur J Pediatr. 1999;158(8):658-61. 
3. Tsukahara H, Takeuchi M, Fujisawa K, Miura M, Hata K, Yamamoto K, Mayumi M. High-turnover osteopenia in preterm infants: determination of urinary pyridinium cross-links of collagen. Metabolism. 1998;47(3):333-5.

4. Backstrom MC, Kuusela AL, Maki R. Metabolic bone disease of prematurity. Ann Med. 1996;28(4):275-82.

5. Embleton N, Wood CL. Growth, bone health, and later outcomes in infants born preterm. J Pediatr. 2014;90(6):529-32.

6. Backstrom MC, Kuusela AL, Koivisto AM, Sievanen $\mathrm{H}$. Bone structure and volumetric density in young adults born prematurely: a peripheral quantitative computed tomography study. Bone. 2005;36(4):688-93.

7. Koo WW, Sherman R, Succop P, Krug-Wispe S, Tsang RC, Steichen JJ, Crawford AH, Oestreich AE. Fractures and rickets in very low birth weight infants: conservative management and outcome. J Pediatr Orthop. 1989; 9(3):326-30.

8. Vachharajani AJ, Mathur AM, Rao R. Metabolic bone disease of prematurity. NeoReviews. 2009;10(8):e402-11.

9. Heaney RP. Effects of caffeine on bone and the calcium economy. Food Chem Toxicol. 2002;40(9):1263-70.

10. Erenberg A, Leff RD, Haack DG, Mosdell KW, Hicks GM, Wynne BA. Caffeine citrate for the treatment of apnea of prematurity: a double-blind, placebocontrolled study. Pharmacotherapy. 2000;20(6):644-52.

11. Natarajan G, Botica ML, Thomas R, Aranda JV. Therapeutic drug monitoring for caffeine in preterm neonates: an unnecessary exercise? Pediatrics. 2007 119(5):936-40.

12. Fredholm BB, Battig K, Holmen J, Nehlig A, Zvartau EE. Actions of caffeine in the brain with special reference to factors that contribute to its widespread use. Pharmacol Rev. 1999;51(1):83-133.

13. Charles BG, Townsend SR, Steer PA, Flenady VJ, Gray PH, Shearman A. Caffeine citrate treatment for extremely premature infants with apnea: population pharmacokinetics, absolute bioavailability, and implications for therapeutic drug monitoring. Ther Drug Monit. 2008;30(6):709-16.

14. Glajchen N, Ismail F, Epstein S, Jowell P, Fallon M. The effect of chronic caffeine administration on serum markers of bone mineral metabolism and bone histomorphometry in the rat. Calcif Tissue Int. 1988;43(5):277-80.

15. Yeh JK, Aloia JF, Semla HM, Chen SY. Influence of injected caffeine on the metabolism of calcium and the retention and excretion of sodium, potassium, phosphorus, magnesium, zinc and copper in rats. J Nutr. 1986; 116(2):273-80.

16. Zanardo V, Dani C, Trevisanuto D, Meneghetti S, Guglielmi A, Zacchello G, Cantarutti $F$. Methylxanthines increase renal calcium excretion in preterm infants. Biol Neonate. 1995;68(3):169-74.

17. Bergman EA, Massey LK, Wise KJ, Sherrard DJ. Effects of dietary caffeine on renal handling of minerals in adult women. Life Sci. 1990;47(6):557-64.

18. Harvey NC, Javaid MK, Arden NK, Poole JR, Crozier SR, Robinson SM, Inskip HM, Godfrey KM, Dennison EM, Cooper C. Maternal predictors of neonatal bone size and geometry: the Southampton Women's survey. J Dev Orig Health Dis. 2010;1(1):35-41.

19. Bosley AR, Verrier-Jones ER, Campbell MJ. Aetiological factors in rickets of prematurity. Arch Dis Child. 1980;55(9):683-6.

20. Blackman NJM, Koval JJ. Interval estimation for Cohen's kappa as a measure of agreement. Stat Med. 2000;19(5):723-41.

21. Koo WW, Gupta JM, Nayanar W, Wilkinson M, Posen S. Skeletal changes in preterm infants. Arch Dis Child. 1982;57(6):447-52

22. Booth JG, Hobert JP. Maximizing generalized linear mixed model likelihoods with an automated Monte Carlo EM algorithm. Journal of the Royal Statistical Society Series B, Statistical Methodology. 1999:265-85.

23. Ofek-Shlomai $N$, Berger I. Inflammatory injury to the neonatal brain - what can we do? Front Pediatr. 2014;2:30.

24. Viswanathan S, Khasawneh W, McNelis K, Dykstra C, Amstadt R, Super DM, Groh-Wargo S, Kumar D. Metabolic bone disease: a continued challenge in extremely low birth weight infants. JPEN J Parenter Enteral Nutr. 2014;38(8): 982-90

25. Schneider PE, Miller HI, Nakamoto T. Effects of caffeine intake during gestation and lactation on bones of young growing rats. Res Exp Med (Berl). 1990;190(2):131-6.

26. Littner Y, Mandel D, Mimouni FB, Dollberg S. Bone ultrasound velocity curves of newly born term and preterm infants. J Pediatr Endocrinol Metab. 2003;16(1):43-7.

27. Aly H, Moustafa MF, Amer HA, Hassanein S, Keeves C, Patel K. Gestational age, sex and maternal parity correlate with bone turnover in premature infants. Pediatr Res. 2005;57(5 Pt 1):708-11.
28. Namgung R, Tsang RC. Factors affecting newborn bone mineral content: in utero effects on newborn bone mineralization. Proc Nutr Soc. 2000;59(1):55-63.

29. Pereira-da-Silva L, Costa A, Pereira L, Filipe A, Virella D, Leal E, Moreira A, Rosa M, Mendes L, Serelha M. Early high calcium and phosphorus intake by parenteral nutrition prevents short-term bone strength decline in preterm infants. J Pediatr Gastroenterol Nutr. 2011;52(2):203-9.

30. Backstrom MC, Kouri T, Kuusela AL, Sievanen H, Koivisto AM, Ikonen RS, Maki M. Bone isoenzyme of serum alkaline phosphatase and serum inorganic phosphate in metabolic bone disease of prematurity. Acta paediatrica (Oslo, Norway: 1992). 2000:89(7):867-73.

31. Yesiltepe Mutlu G, Kirmizibekmez H, Ozsu E, Er I, Hatun S. Metabolic bone disease of prematurity: report of four cases. J Clin Res Pediatr Endocrinol. 2014;6(2):111-5.

32. Hellstern G, Poschl J, Linderkamp O. Renal phosphate handling of premature infants of 23-25 weeks gestational age. Pediatr Nephrol. 2003; 18(8):756-8.

33. Ghannam NN, Hammami MM, Bakheet SM, Khan BA. Bone mineral density of the spine and femur in healthy Saudi females: relation to vitamin D status, pregnancy, and lactation. Calcif Tissue Int. 1999;65(1):23-8.

\section{Submit your next manuscript to BioMed Central and we will help you at every step:}

- We accept pre-submission inquiries

- Our selector tool helps you to find the most relevant journal

- We provide round the clock customer support

- Convenient online submission

- Thorough peer review

- Inclusion in PubMed and all major indexing services

- Maximum visibility for your research

Submit your manuscript at www.biomedcentral.com/submit
) Biomed Central 